\title{
Posterior cruciate ligament. cortical tibial fixation
}

\begin{abstract}
The difficulties of the techniques of reconstruction of de Posterior Cruciate Ligament (PCL) are widely known.
\end{abstract}

Objectives: To present our technique of retrograde tibial fixing, and analyze retrospectively if we have improved the final result.

Material and Method: In a group of 110 surgical patients for PCL operated with different techniques we did a retrospective study in 96 with X-ray posterior drawer when they returned to work. 14 patients were excluded because they did not meet those conditions.

Results: The X-ray posterior drawer test had differences statistically significant between our technique and the previous ones, which were done with bone-patellar tendon- bone and quadrupled hamstrings fixed with screws.

Conclusion: Our technique has simplified the surgery; its duration was shortened and therefore allows us to do other simultaneous ligament reconstructions. It has improved the posterior drawer test objectively.
Volume II Issue I - 2019

\section{Rodolfo Horacio Alonso}

Argentina

Correspondence: Rodolfo Horacio Alonso, Lobos 249,Wilde, Buenos Aires, Código Postal: 1875, Argentina,

Email rodolfohalonso@gmail.com

Received: July 15, 2017 | Published: January 31, 2019

Keywords: PCL, Cortical Tibial Fixation

Level of evidence: Level III. Retrospective comparative study.

\section{Introduction}

PCL reconstruction is demanding, with different techniques available. First Bone-Tendon-Bone graft $(\mathrm{BTB})^{1-7}$ was chosen, with important technical difficulties such as sometimes short graft length, because at the moment to turn and introduce one of the bone parts into the femoral tunnel from distal to proximal, the other bone part got out from the tibial tunnel and it was very difficult to get it reintroduced.. Another difficulty was to control the location of the screw at the end of the tibial tunnel. Then Quadrupled Hamstrings $(\mathrm{QH})$ graft $^{8-22}$ was used, fixed with screws, with which the technique was much easier, the length of the graft was enough (with the need even to place a screw in the depth of the tibial tunnel) and because of its flexibility there was not difficulty in introduction it into the femoral tunnel.

With these first two techniques after the surgery the knee had no clinical PDT, but when the immobilization with the splint was removed after 8 weeks a clinical PDT was evident, and then at the medical discharge the radiographic PDT was greater than $5 \mathrm{~mm}$, exceeding the average in medical publications. There were two surgeries not included in this study, with Quadricipital graft, ${ }^{23-25}$ and because of its length it was necessary to fix the bone plug into the depth of the tibial tunnel (same problem as with BTB), and with a little thickness at the end of the graft to fix it inside the femoral tunnel with equal outcome at discharge, the presence of greater than $5 \mathrm{~mm}$ PDT ( $7.5 \mathrm{~mm}$ average).

At that point, it was thought that the final result was caused by fault in the tibial fixation, and then it was decided to use a device to hang in a stirrup the $\mathrm{HG}$ and attach it to the tibial cortical in the retrograde form (which in addition gave the benefit of not having to control the position of a tibial screw). Two devices were used, designed to suspend tendons in the femur to ACL reconstruction (as an Endobutton), first SAR Bone, rigid and long only up to $20 \mathrm{~mm}$ (Figure 1), and when its production was discontinued E-SOLID was used, which because it has a longer and articulated stirrup, is best directed along the tibial tunnel (Figure 2).

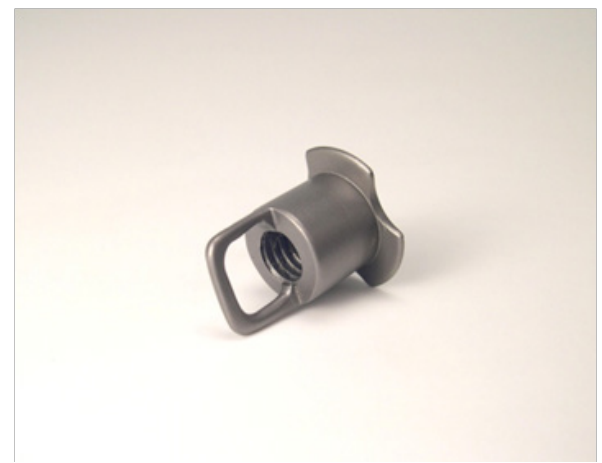

Figure I SAR-Bone device: it shows the stirrup to hang tendons and flaps to lock at the cortical.

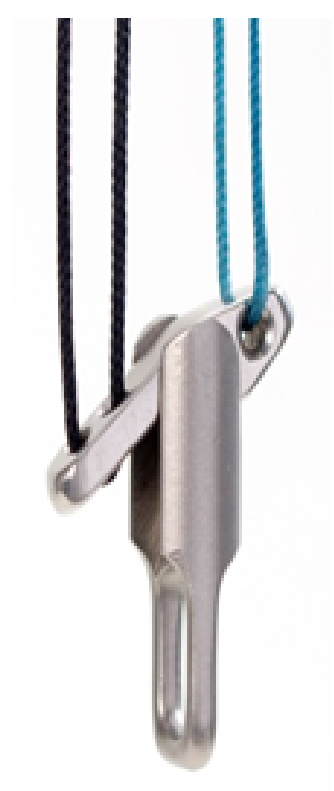

Figure 2 E-SOLID device: with stirrup to hang tendons and articulated bracket to lock at the cortical. 
At that time also vision optics or instrumental via the posteriorinner passage was left aside for every surgery. Instead anterior approach was used. The aim is to present a new technique for PCL reconstruction. And to analyze retrospectively the result obtained with techniques previously employed and the technique which is showed, to lower the PDT after the patient discharge.

\section{Materials and methods}

110 reconstructions were done from May 1996 to December 2014.

Inclusion criteria: patients presenting ruptures type III (more than $10 \mathrm{~mm}$ of PDT), or type II (between 5 and $10 \mathrm{~mm}$ in PDT with symptoms that prevented their return to work), isolated or combined, and were assessed at the time of registration for return to work using radiographic PDT measured in $\mathrm{mm}$.

The PDT was measured in mm with natural size Rx superimposing the Rx of the operated knee and the contralateral (Figure 3\&4).

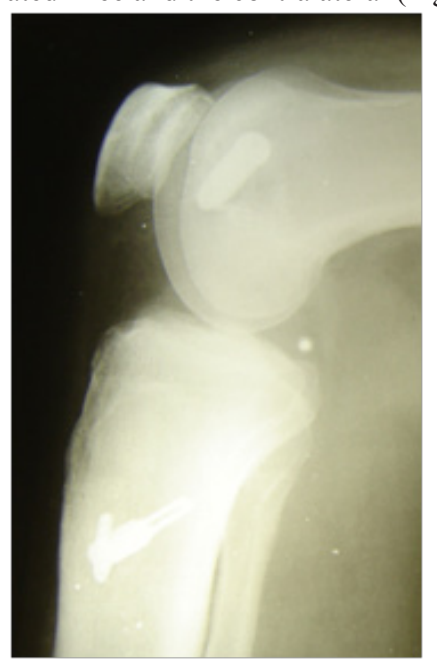

Figure 3 PDT Rx of the operated knee at discharge. E Solid device. The correct location of the tibial tunnel without use of posterior internal approach can be seen..

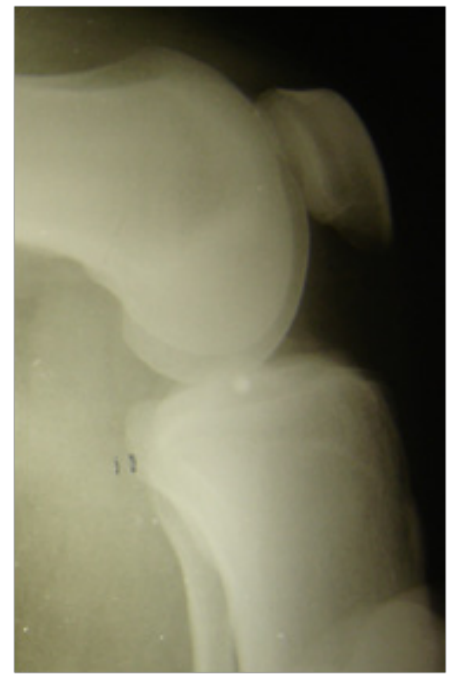

Figure 4 PDT Rx in contralateral knee less than $5 \mathrm{~mm}$.

Technique: 1) Knee in $90^{\circ}$. Vertical incision medial at the Anterior Tibial Tubercle (ATT) to take out the Hamstrings Graft. As assistant prepares the $\mathrm{QH}$ passing the Hamstrings through the device bracket and suturing them to themselves (Figure 5). The tourniquet is inflated.

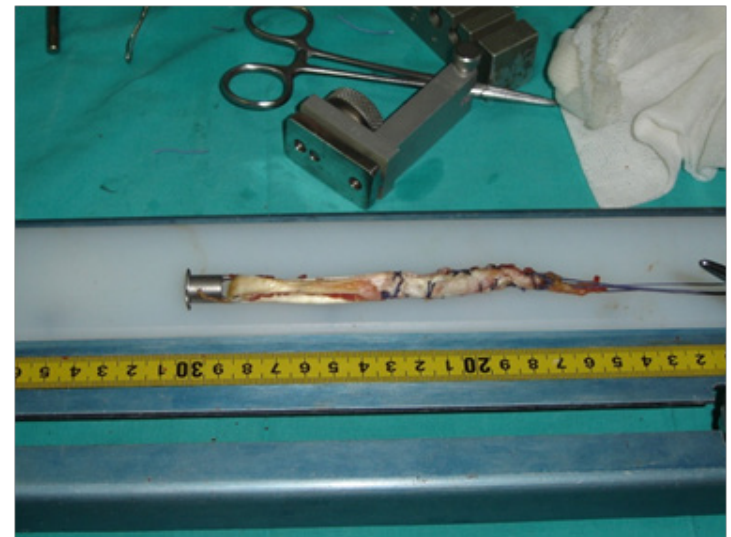

Figure $5 \mathrm{QH}$ graft prepared with Sar Bone device.

2) Arthroscopy by anterior-lateral approach, meniscal surgery if required. Cleaning of remains of PCL in femur and tibia, seeing and touching the end of the posterior slope, (Usually it is necessary to temporarily exchange the optic to medial and the instruments to lateral).

3) The optic by anterior lateral approach better locates us in the knee than the posterior medial, since it is the way that the arthroscopy is usually performed, and gives more security since the posterior capsule is permanently seen, which is favored by tibial posterior translation because of the relaxed ACL. By anterior-medial approach on the edge of the posterior tibial slope a special guide for PCL with safety device which does not allow the pin to go beyond the tip of the Guide is set (Figure 6A\&B), the guide is regulated to lay it in the tibial cortical most distal possible position to avoid interference with a possible tunnel of ACL reconstruction. The pin is inserted with puncher until it stops and soft hammer blows complete the passage through the cortex. A protector cap is placed over the pin, and tunnel is done with bit $1 \mathrm{~mm}$ grater that the graft diameter). The tunnel is compacted with device of equal diameter, and with adequate scraper the joint tunnel mouth is rounded to prevent ruptures of the graft in the angle.

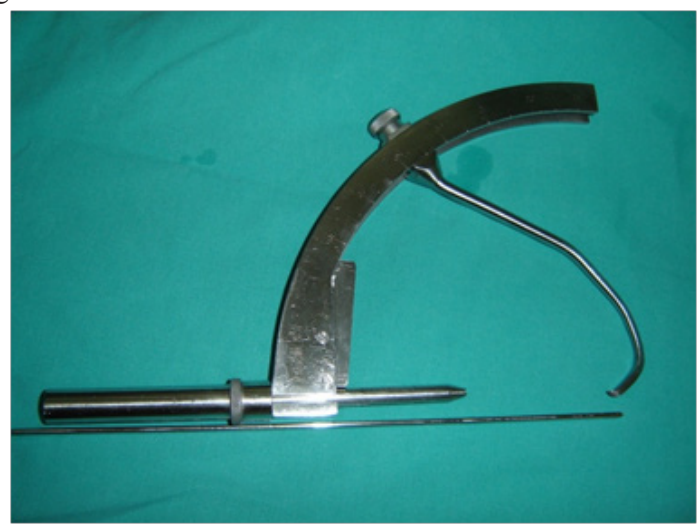

Figure 6(A) Special PCL tibial Guide. It has a stop that regardless of the length of the tunnel prevents the pin from passing the tip of the Guide avoiding nerve and vascular injuries.

4) With the same guide a pin is placed in the femoral condyle in an out in way, so that it gets out intra-articular $5 \mathrm{~mm}$ from the 
osseous-cartilaginous limit in the original insertion of the anteriorlateral fasciculus at time 1.30 for the right knee and 10.30 for the left (Figure 7). A protector cup is again placed so that the bit will not damage structures, and a tunnel outside inside, according to graft diameter is done. A compactor is passed, and the intra-articular mouth is scrapped. (If the ACL is also broken, at this time the proper tunnels are done with appropriate guidelines).

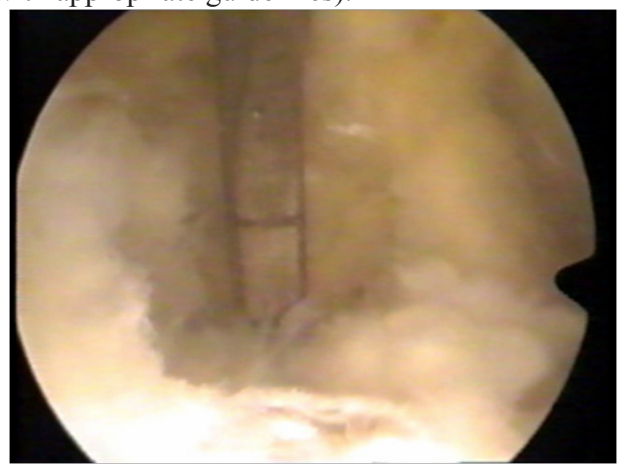

Figure 6(B) Vision of the tip of the tibial guide behind the rear slope with optics via anterior lateral.

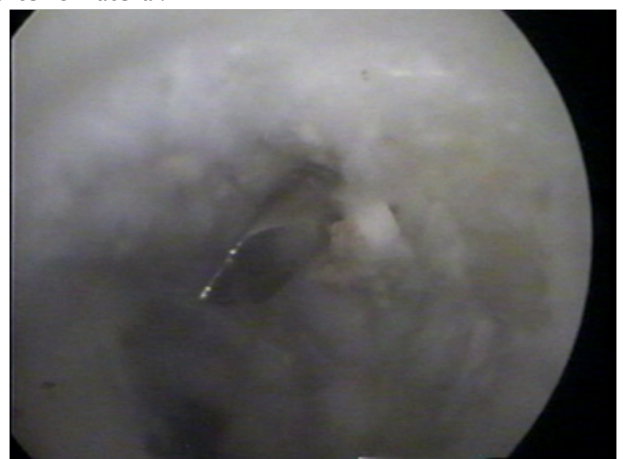

Figure 7 Location of the pin for the femoral tunnel passed outside inside with the same tibial Guide.

5) A double wire is passed in tibia outside inside, it is led with the tracer until the intra-articular hole of the femoral tunnel where it is fished with a hook outside (Figure 8 A\&B). Another double wire on the outside of the knee is engaged, and is carried distally (femoral tunnel - intra-articular - tibial tunnel), the loop remaining out of the tibial hole.

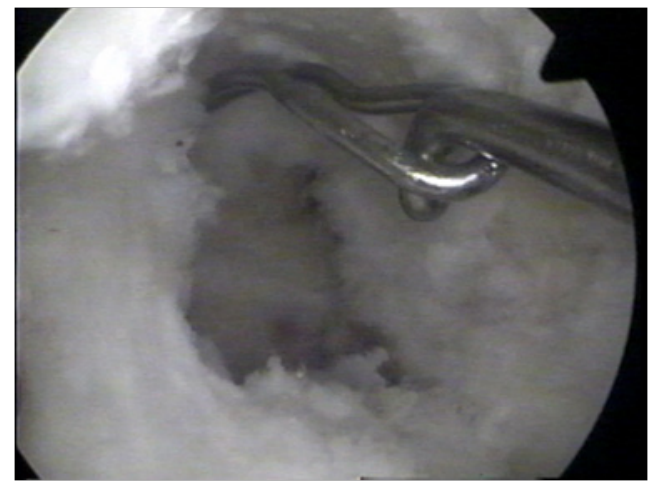

Figure $\mathbf{8}(\mathbf{A})$ Passage of the first wire by the tibial tunnel outside inside, driven by the tracer to be presented against the femoral tunnel.

6) Through the wire loop tractor threads are passed, the graft is raised distal to proximal to the outside of the inner condyle (Figure 9 A\&B), until the tibial device gets locked in the cortical.

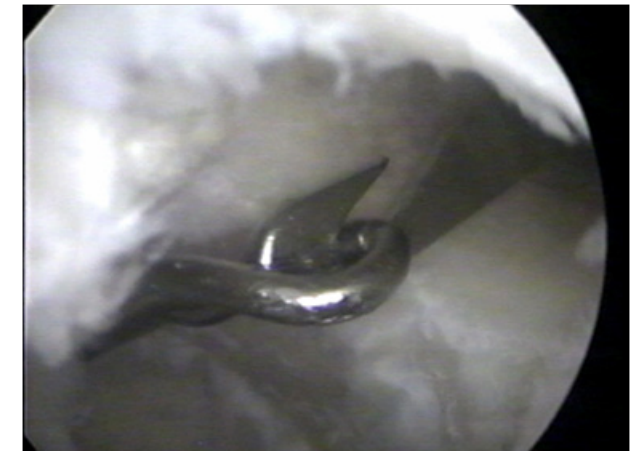

Figure $\mathbf{8}(\mathbf{B})$ In the intra-articular mouth of the femoral tunnel the first wire is engaged with a hook and carried out to have it passed along the path of the PCL with the loop outside of the femur.

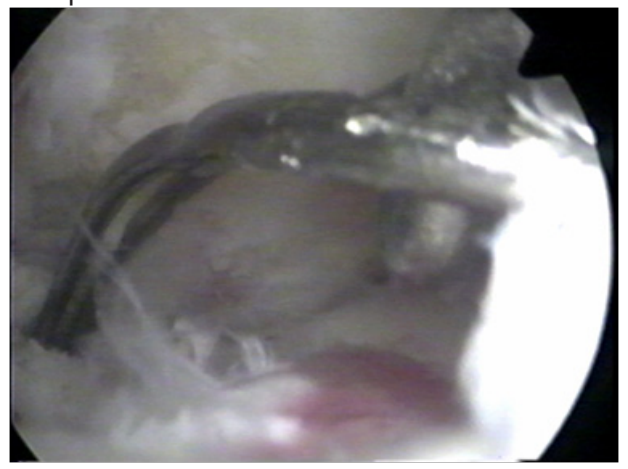

Figure $\mathbf{9}(\mathbf{A})$ Once the second wire is hooked to the first, out of the femoral tunnel, it is carried to distal so it rests with its loop on the outside of the tibial tunnel.

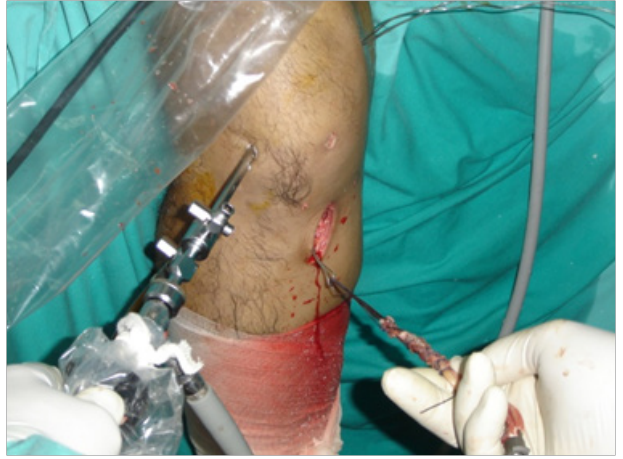

Figure 9(B) By the second wire bending graft threads are passed to subsequently raise it through tibial and femoral tunnels.

7) Maneuver of tightening is done: while assistant pulls the graft strongly, the surgeon with one forearm behind the leg performs anterior drawers, and with the other hand on the ankle carries out knee flexion-extensions several times (Figure 10), so that the graft further progresses within the tunnels.

8) Screw guide is passed into femoral tunnel so that that it does not penetrate the graft and is left between it and the wall of the tunnel in order not to block the screw. Knee in $70^{\mathrm{a}}$ and under maximum stress (anterior drawer with forearm behind the leg), the assistant places tendon osseous interference screw of the diameter of the tunnel outside inside, leaving the system as shown in Figure 11 and radiographic controls Figure 12. The stability is checked in flexion and extension. In case of rupture of both Cruciates, after passing the PCL graft, the BTB graft is introduced and fixed in ACL femur tunnel, then in 70 degrees of flexion and reduction of step off, the PCL graft is fixed 
in femur with a screw out in, and so is the ACL graft in $70^{\circ}$ in tibia, according to Fanelli recommendation ${ }^{35}$ If there is also a collateral ligament injury, the hemostatic device is released and the collateral ligament is repaired without having to re-inflate it.

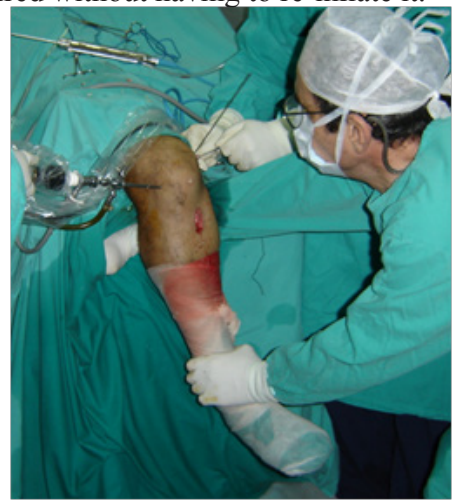

Figure 10 Once the graft is hoisted, while the assistant pulls it, the surgeon makes maneuver of tension: with a forearm behind the leg doing strong anterior drawer and with the other hand doing knee flexion-extensions numerous times.

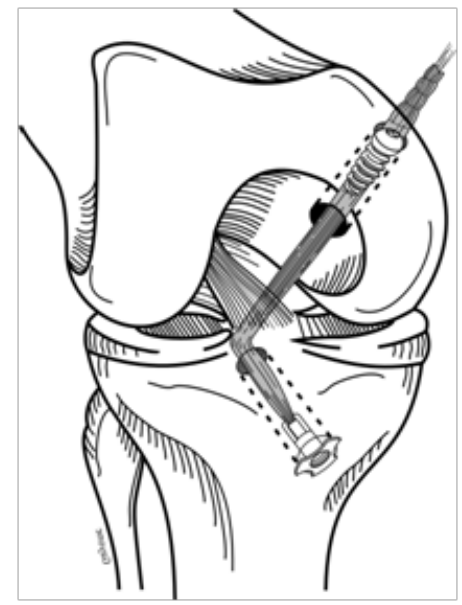

Figure II Drawing of the system with graft fixed in tibia with Sar Bone and in femur with interference screw, from outside to inside.

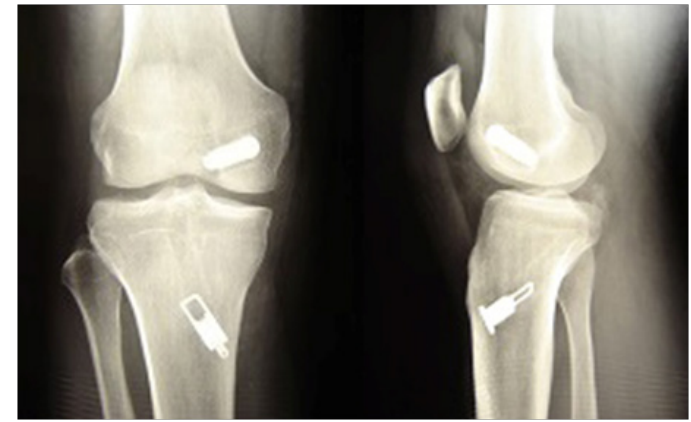

Figure I 2 Postoperative Rx control, with E Solid, showing again that the tibial tunnel is correctly located without the need to use posterior internal approach.

9) Inguinal malleolar brace fixed in knee extension with back leg discharge to relax the LCP for 4 weeks, then progressive mobility, support with crutches at week six, removal of splint at week eight, progressive removal of crutches according to muscle strength and plan of rehabilitation for 2 to 3 more months.
With this technique SAR-Bone device was used in 53 knees (Figure $1 \& 5)$. Due to discontinuity in the production of the Sar Bone, the $\mathrm{E}$ Solid device was used in the following 16 surgeries (Figure $2 \& 12$ ).

\section{Results}

Over 110 PCL surgeries 96 reconstructions ( 92 men and 4 women) were included, with average age 33.6 years (range 17 to 55 years), and 12 patients who had not been discharged, or were lost during the treatment were excluded. The result in the first surgeries with different techniques was:

First group: BTB graft fixed with two interference screws ${ }^{1-7}$ consists of 13 patients with average age 33.4 years (range 17 to 52 years), with Rx PDT at discharge of $8.08 \mathrm{~mm}$. (range 7 to $11 \mathrm{~mm}$ ).

Second group: $\mathrm{QH}$ graft $^{8-24}$ fixed with interference screws in femur and tibia, in some cases plus staple tibial, in 4 cases double fascicle, consists of 14 patients ( 1 female) with average age 31.7 years (range 22 to 44 years) with Rx PDT at discharge of $8.07 \mathrm{~mm}$. (range 3-11 mm).

Third group: Two types of devices that are attached to the tibial cortical and have a stirrup from which hangs a $\mathrm{QH}$ graft folded over itself were used. This last group includes 69 patients, 66 men and 3 women with average age 34.2 years (range 19 to 55 years) with an $\mathrm{Rx}$ PDT at discharge of $4 \mathrm{~mm}$ (range 0 to $14 \mathrm{~mm}$ ).

Since July 2004 with this technique significantly reduction of PDT at discharge has been achieved, with an average within the grade I (0-5 mm), similar to other publications.

In the statistical analysis, the variable PDT does not present a normal distribution so the non-parametric test of Kruskal Wallis was used, and significant differences were found. To compare pairs to groups the Mann-Whitney test was used, and because multiple comparisons were made, the Bonferroni correction was used to handle the error of type 1 . No significant differences were found between first and second groups treatments $(\mathrm{Pv}=0,430)$, but by comparing each of the first two with the technique of retrograde cortical tibial fixation, significant differences were found $(\mathrm{Pv}<0.001)$ (Table 1).

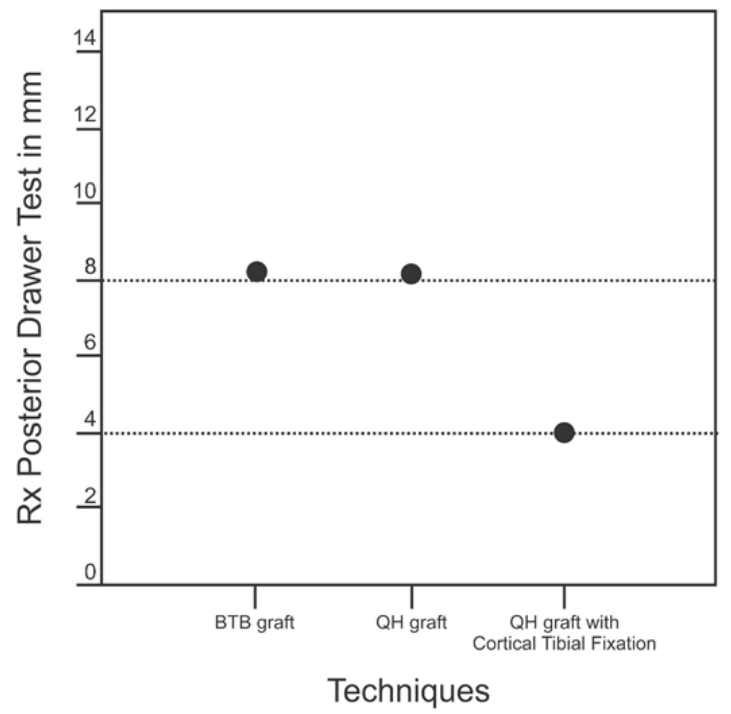

Table I Graph of Rx PDT in mm. comparing different techniques 


\section{Discussion}

In patients with work-related injuries subjective tests are unreliable, and patients are lost to long term follow-up, therefore to evaluate the final results with the new technique at discharge $\mathrm{Rx}$ PDT measured in $\mathrm{mm}^{25-28}$ has been used. The results in the two first groups of surgeries was: in 13 patients using BTB graft fixed with two interference screws the Rx PDT was $8.08 \mathrm{~mm}$ at discharge, and in 14 reconstructions with $\mathrm{QH}$ graft, fixed with interference screws, in some cases plus staple tibial, in 4 cases double fascicle, the Rx PDT was $8.07 \mathrm{~mm}$ at discharge.

It was thought that because the tibial tunnel was locked distal in the cortical where the mineral bone density is minor, it caused the loss of fixation obtained at the end of the surgical procedure ${ }^{29-33}$ and so two devices that allowed to suspend QH grafts of a Stirrup were used successively. Also the difficulties to see the final position of the tibial screw at the bottom of a long tunnel were solved simultaneously, avoiding the introduction of the optic into the tibial tunnel to view the screw position or Rx controls in case of doubt, (once in a BTB reconstruction a screw was surpassing the posterior tibial cortical in half of its length, without vascular or nervous complications). In cases of rupture of both cruciate ligaments ${ }^{34-36}$ after seeing through the anterior-lateral approach the posterior slope with the PCL insertion, reconstruction of both ligaments began without doing posterior internal approach. Then in cases of PCL ruptures isolated, favored by ACL laxity, relaxed by the back subluxated tibia, it was possible to see and clean the rear slope, see the tibial Guide and locate the wire Guide at the angle where the pending ends, with the lens via anterior lateral side and the instrumental anterior medial. Since then the accessory posterior-medial approach has not been used in our surgeries. We would like to emphasize that there is no consensus on the exact location of the tibial tunnel, and that small variations in anterior-posterior position do not alter the final result. ${ }^{37}$

In 69 patients, treated with the technique in which graft was fixed in cortical tibial and in femur with interference screw, Rx PDT at the discharge was $4 \mathrm{~mm}$. Although at the end of surgery the knee was stable, at the patient discharge a satisfactory PDT less than $5 \mathrm{~mm}$, similar to results in published techniques for PCL had not been achieved. Fixing the graft to the tibial cortical, an immovable and rigid fixation was achieved. The possibility to pull directly from the proximal graft made it possible to tighten it further, avoiding forcing the tibia backwards in the placement of staples or screws when the final fixing is tibial, all of which has contributed to stability at discharge within Group I from 0 to $5 \mathrm{~mm}$. Tibial cortical fixation also freed from doubts a tibial screw position.

On the other hand avoiding posterior internal approach, has also helped to shorten the operating time by $50 \%$, so we can currently do this surgery by inflating the hemostatic device once, and to do at the same time reconstruction of the ACL and/or Collateral Ligaments if necessary. It is debatable whether the results of the technical inlay ${ }^{38-41}$ are better. This could be because of strong tibial fixation, or because having a single tunnel produces less friction and tightens more graft, but our technique is simpler and does not require the opening of the popliteal area. The weak points of this presentation are that only subsequent Rx PDT have been compared, that the measurements were not made by an independent observer, and the short follow-up of patients, only until discharge.

\section{Conclusion}

The reconstruction of the PCL with the described technique has improved radiographic final PDT which was the stated objective and has simplified the surgery, shortening the duration of the procedure, and allowing simultaneous ligament reconstructions.

\section{Acknowledgements}

None.

\section{References}

1. Hughston JC, Bowden JA, Andrews Jr, et al. Acute tears of the Posterior Cruciate Ligament. Results of Operative Treatment. J Bone Joint Surg Am. 1980;62(3):438-450.

2. Clancy WG Jr, Shelbourne KD, Zoellner GB, et al. Treatment of Knee Joint Instability Secondary to Rupture of the PCL. Report of a New Procedure. J Bone Joint Surg Am.1983;65(3):310-322.

3. Clancy WG Jr. Arthroscopic Assisted Posterior Cruciate Ligament Reconstruction Using Autologous Patellar Tendon Graft. Sport Medicine. 1993;1(2):129-135.

4. Ranalleta A. Anatomic Basics for PCL reconstruction. Revista Argentina de Artroscopia. 1995;2:214-220.

5. Barrera Oro A, Lapera M, Gigante F. Posterior Cruciate Ligament Reconstruction. Arthroscopic treatment. Revista de la Asociación Argentina de Artroscopía. 1997;4:39-43.

6. Barrera Oro A, Lapera MF, Gigante F, et al. Multiple Knee lesions. Revista Argentina de Artroscopía. 1998;5:24-31.

7. Skiya JK, Kurtz CA, Carr DR. Transtibial and Tibial Inlay Doublebundle Posterior Cruciate Ligament Reconstruction: Surgical Technique Using a Bifid Bone-patellar Tendon-bone Allograft. Arthroscopy. 2004;20(10):1095-1100.

8. Lipscomb AB, Anderson AF, Norwig ED, et al. Isolated Posterior Cruciate Ligament Reconstruction: Long-term results. Am J Sports. 1993;21(4):490-496.

9. Fanelli GC, Gianotti BF, Edson CJ. Current Concepts Review: The PCL Arthroscopic Evaluation and Treatment. Arthroscopy. 1994;10:673688.

10. Fanelli GC, Giannotti BF, Edson CJ. Arthroscopically Assisted Combined Anterior and Posterior Cruciate Ligament Reconstruction. Arthroscopy. 1996;12(1):5-14.

11. Kim SH, Kim HK, Kim HJ. A Modified Endoscopic Technique for Posterior Cruciate Ligament Reconstruction Using Allograft. Arthroscopy. 1998;14(6):643-648.

12. Ibrahim SA. Primary Repair of the Cruciate and Collateral Ligaments after Traumatic Dislocations of the Knee. J Bone Joint Surg Br 1999;81(6):987-990.

13. Makino A, Muscolo L, Costa Paz M, et al. PCL Reconstruction with double fascicle. Revista Argentina de Artroscopía. 2000;7:58-62.

14. Fanelli GC. Arthroscopic PCL Reconstruction Transtibial Tunnel Technique: Surgical Technique and Results. Arthroscopy. 2002;18:44 49.

15. Chen $\mathrm{CH}$, Chen WJ, Shih $\mathrm{CH}$. Arthroscopic Reconstruction of the Posterior Cruciate Ligament with Quadruple Hamstring Tendon Graft: a Double Fixation Method. J Trauma. 2002;52(5):938-945.

16. Scranton PE, Bagenstose JE, Lantz BA, et al. Quadruple Hamstring 
Anterior Cruciate Ligament Reconstruction: A Multicenter Study. Arthroscopy. 2002;18(7):715-724.

17. Wang CJ, Chan YS, Weng LH. Posterior Cruciate Ligament Reconstruction Using Hamstring Tendon Graft With Remnant Augmentation. Arthroscopy. 2005;21(11):1401.

18. Chan YS, Yang SC, Chang CH, et al. Arthroscopic Reconstruction of the Posterior Cruciate Ligament with Use of a Quadruple Hamstring Tendon Graft with 3- to 5- Year Follow-up. Arthroscopy. 2006;22(7):762-770.

19. Chen CH, Chuang TY, Wang KC, et al. Arthroscopic Posterior Cruciate Ligament Reconstruction With Hamstring Tendon Autograft: Results With a Minimum 4-year Follow-up. Knee Surg Sports Traumatol Arthrosc. 2006;14(11):1045-1054.

20. Fanelli GC, Edson CJ, Reinheimer KN, et al. Arthroscopic SingleBundle versus Double-bundle Posterior Cruciate Ligament Reconstruction. Arthroscopy. 2008;6:e26.

21. Kim SH, Kim SJ, Chun YM, et al. Paper \# 247: Clinical Comparison of Remnant-Preserving and Conventional Technique in PCL Reconstruction. Arthroscopy. 2011;10:e 235.

22. Brand J, Hamilton D, Selby J, et al. Biomechanical Comparison of Quadriceps Tendon Fixation with Patelar Tendon Bone Plug Interference Fixation in Cruciate Ligament Reconstruction. Arthoscopy. 2000;16(8):80-812.

23. Chen $\mathrm{CH}$, Chen WJ, Shih CH. One-Incision Endoscopic Technique for Posterior Cruciate Ligament Reconstruction with Quadriceps TendonPatellar Bone Autograft. Arthroscopy. 2001;17(3):329-332.

24. Chen $\mathrm{CH}$, Chen WJ, Shih $\mathrm{CH}$. Arthroscopic Reconstruction of the Posterior Cruciate Ligament: A Comparison of Quadriceps Tendon Autograft and Quadruple Hamstring Tendon Graft. Arthroscopy. 2002;18(6):603-612.

25. Margheritini F, Mancini L, Mauro CS, et al. Stress Radiography for Quantifying Posterior Cruciate Ligament Deficiency. Arthroscopy. 2003;19(7):706-711.

26. Schulz MS, Russe K, Lampakis G, et al. Reliability of Stress Radiography for Evaluation of Posterior Knee Laxity. Am J Sports Med. 2005;33(4):502-506.

27. Jung TM, Reinhardt C. Stress Radiography to Measure Posterior Cruciate Ligament Insufficiency: a Comparison of Five Different Techniques. Knee Surg Sports Traumatol Arthrosc. 2006;14(11):1161121.

28. Garavaglia G, Lubbeke A, Dubois-Ferriere V, et al. Accuracy of Stress Radiography Techniques in Grading Isolated and Combined Posterior Knee Injuries: A cadaveric study. Am J Sports Med. 2007;35(12):20512056.
29. Singhalat W, Lawhorn KW, Howell SM, et al. How Four Weeks of Implantation Affect the Strength and Stiffness of a Tendon Graft in a Bone Tunnel: A Study of Two Fixation Devices in an extra articular Model in Ovine. Am J Sports Med. 2002;30(4):506-513.

30. Scheffler SU, Südkamp NP, Göckenjan A, et al. Biomechanical Comparison of Hamstring and Patellar Tendon Graft Anterior Cruciate Ligament Reconstruction Techniques: The Impact of Fixation Level and Fixation Method Under Cycling Loading. Arthroscopy. 2002;18(3):304-315.

31. Song EK, Rowe SM, Chung JY, et al. Failure of Osteointegration of Hamstring Tendon Autograft after Anterior Cruciate Ligament Reconstruction. Arthroscopy. 2004;20(4):424-428.

32. Weimann A, Rodieck M, Zantop T, et al. Primary Stability of Hamstring Graft Fixation with Biodegradable Suspension Versus Interference Screws. Arthroscopy. 2005;21(3):266-274.

33. Prodromos CC, Joyce BT, Shi K, et al. A Meta-Analysis of Stability after Anterior Cruciate Ligament Reconstruction as a Function of Hamstring versus Patellar Tendon Graft and Fixation Type. Arthroscopy. 2005;21(10):1202-1208.

34. Fanelli GC, Orcutt DR, Edson CJ. The Multiple-Ligament Injured Knee: Evaluation, Treatment and Results. Arthroscopy. 2005;21(4):471-486.

35. Strobel MJ, Schulz MS, Petersen WJ, et al. Combined Anterior Cruciate Ligament, Posterior Cruciate Ligament, and Posterolateral Corner Reconstruction With Autogenous Hamstring Grafts in Chronic Instabilities. Arthoscopy. 2006;22(2):182-192.

36. Hayashi R, Kitamura N, Kondo E, et al. Simultaneous Anterior and Posterior Cruciate Ligament Reconstruction in Chronic Knee Instabilities: Surgical Concepts and Clinical Outcome. Knee Surg Sports Traumatol Arthrosc. 2008;16(8):763-769.

37. Nicodeme JD, Löcherbach C, Jolles BM. Tibial Tunnel Placement in Posterior Cruciate Ligament Reconstruction: a Systematic Review. Knee Surg Sports Traumatol Arthrosc. 2014;22(7):1556-1562.

38. Berg E. PCL Tibial Inlay Reconstruction. Arthroscopy. 1995;11:69-76.

39. Kim SJ, Choi CH, Kim HS. Arthroscopic posterior cruciate ligament tibial inlay reconstruction. Arthroscopy. 2004;20:149-154.

40. Seon JK, Song EK. Reconstruction of Isolated Posterior Cruciate Ligament Injuries: A Clinical Comparison of the Transtibial and Tibial Inlay Techniques. Arthroscopy. 2006;22(1):27-32.

41. MacGillivray JD, Shubin Stein BE, Park M, et al. Comparison of Tibial Versus Transtibial Techniques for Isolated Posterior Cruciate Ligament Reconstruction: Minimum 2- Year Follow-up. Arthroscopy. 2006;22(3):320-328. 